\title{
ANALISE METALOGRÁFICA DE FIXADORES EM VEÍCULOS DE ORIGEM CHINESA ${ }^{1}$
}

\author{
Ana Paula Piris Rodrigues ${ }^{2}$ \\ André Ricardo Moraes Rodrigues Serra ${ }^{2}$ \\ Marcos Chogi lano ${ }^{3}$
}

\section{Resumo}

Numa economia globalizada, a oferta de produtos das mais diversas origens, principalmente de países emergentes, está cada vez mais presente no cotidiano dos consumidores. Um exemplo típico é o mercado automobilístico, montadoras de origem chinesa e coreana estão cada vez mais presentes com ofertas de produtos mais acessíveis para os consumidores. Preço convidativo, maior número de itens de série e prazos de garantia maiores, são atrativos instigantes destes produtos. Em 2007, quando chegaram os primeiros carros chineses no Brasil a repercussão foi modesta, foram vendidos 143 unidades, $0,006 \%$ do mercado total de veículos leves comercializados. No ano de 2009, foram entregues 3243 unidades, passando a representas $0,1 \%$ do mercado. Número ainda pequeno no cenário nacional. Segundo a Abeiva (Associação Brasileira dos Importadores de Veículos Automotores), 17266 veículos novos de origem chinesa foram comercializados no Brasil em 2010. Neste trabalho, foram analisados elementos de fixação de rodas de veículos provenientes de montadoras Chinesas. Imagens interessantes das estruturas foram capturadas e analisadas.

Palavras-chave: Fixadores; Metalografia.

\section{METALLOGRAPHIC ANALYSIS OF THE CHARACTERISTICS OF FASTENING ELEMENTS VEHICLE AUTOMAKERS OF CHINESE ORIGIN}

\section{Abstract}

In a globalized economy, the supply of products from various origins, mainly from emerging countries, is increasingly present in everyday consumer. A typical example is the automobile market, automakers origin Korean and Chinese are increasingly present with product offerings more and a longer warranty periods, are the attractions of these products. In 2007, when the first cars Chinese arrived in Brazil the effect was modest, 143 units were sold, $0.006 \%$ of the market for light vehicles marketed. In 2009, 3.243 units were delivered, now representing $0.1 \%$ of the market. Number still small on the national scene. According to Abeiva (Brazilian Association of Motor Vehicles), 17.266 new vehicles of Chinese origin were sold in Brazil in 2010. In the study, we analyzed fastening elements Wheel vehicles from of Chinese automakers. Images of the structures were captured and analyzed.

Key words: Fasteners; Metallography.

1 Contribuição técnica ao $68^{\circ}$ Congresso Anual da ABM - Internacional, 30 de julho a 2 de agosto de 2013, Belo Horizonte, MG, Brasil.

2 Graduando em Tecnologia Mecânica, Faculdade de Tecnologia de Sorocaba "José Crespo Gonzales", Sorocaba, SP, Brasil.

3 Doutorado em Engenharia Mecânica, Professor Associado II, Faculdade de Tecnologia de Sorocaba "José Crespo Gonzales", Sorocaba, SP, Brasil. 


\section{INTRODUÇÃO}

Em 2007, quando chegaram os primeiros carros chineses no Brasil a repercussão foi modesta, foram vendidos 143 unidades, 0,006\% do mercado total de veículos leves comercializados. No ano de 2009, foram entregues 3243 unidades, passando a representas $0,1 \%$ do mercado. Número ainda pequeno no cenário nacional. Segundo a Abeiva (Associação Brasileira dos Importadores de Veículos Automotores), 17266 veículos novos de origem chinesa foram comercializados no Brasil em 2010. Neste trabalho, serão analisados elementos de fixação de rodas de veículos provenientes de montadoras Chinesas. Objetivando determinar as características metalográficas (micro e macroestrutura) das ligas metálicas que compõe estas peças, além da analise da fluência do material proporcionada pela deformação na confecção.

Segundo a Anfavea ${ }^{(1)}$ e Senha para o futuro: (2) "no ano de 2010 o Brasil comercializou 3,51 milhões de veículos, apresentando um crescimento de $11,9 \%$ em relação ao ano anterior. Deste montante, 19\% foram automóveis importados, um número significativo, uma vez que em 2005 eles representavam apena 5,1\% do mercado. Sem dúvidas um dos grandes impulsionadores destes números foram os automóveis provenientes de países como China, Coréia e Japão".

O interesse por carros importados cresce na medida em que são oferecidos mais acessórios como itens de série, garantias maiores e principalmente preços acessíveis para a maioria do mercado consumidor. Segundo Miragaya, ${ }^{(3)}$ chineses cresceram 608\% no Brasil em 2010(4) e aPÓLO Junior:(5) "em contra partida ainda permanece certa resistência e temeridade na aquisição destas novidades pelo histórico de montadoras estrangeiras que comercializaram seus produtos por certo período e não correspondem as expectativas com o pós-venda". Outro motivo que gera insegurança no consumidor é relacionado a qualidade e consequente segurança destes veículos.

Para superar estas dificuldades e desconfiança, montadores que antes traziam os automóveis de fora, prometem se instalarem e produzir aqui. Segundo os Chineses cresceram 608\% no Brasil em 2010:(4) "outras medidas para superarem suas deficiências tecnológicas são as "joint-venture" com montadoras já renomadas, alem de contratarem estúdios de "design" europeus famosos por desenharem carros esportivos".

Os objetivos deste trabalho são: determinar as características dos fixadores utilizados em rodas dos automóveis, comparar as composições químicas destes elementos, verificar as durezas destes materiais e correlaciona-las.

\section{MATERIAIS E MÉTODOS}

Neste trabalho foram analisados fixadores das rodas de automóveis de origem montadoras de origem chinesa:

- amostra 1 - montadora A;

- amostra 2 - montadora B, modelo do carro X;

- amostra 3 - montadora B, modelo do carro Y;

- amostra 4 - montadora B, modelo do carro Z; e

- amostra 5 - montadora C.

A técnica empregada na observação das microestruturas dos aços estudados foi a microscopia ótica, onde um feixe de luz visível incide paralelamente ao eixo do microscópio sobre a amostra e é refletida através de um sistema de espelhos 
chegando até o observador. O modelo utilizado neste estudo foi o microscópio metalográfico binocular invertido.

Segundo Rohde ${ }^{(6)}$ e Samuels: ${ }^{(7)}$ as amostras foram seccionadas no sentido longitudinal (Figura 1) pelo policorte "Cut-off" que utilizou um disco abrasivo de alumina com refrigeração forçada, O disco abrasivo utilizado foi o 3045, indicado para aços até $0,45 \%$ C.

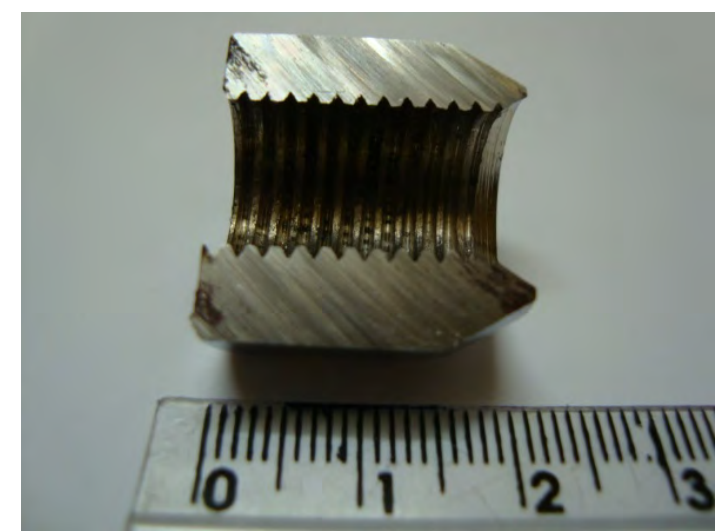

Figura 1. Fixador cortado no sentido longitudinal

A operação de embutimento foi realizada com o equipamento, que acondicionou a amostra no baquelite através de temperatura e pressão da ordem de $125 \mathrm{kgf} / \mathrm{mm}^{2}$ a $150 \mathrm{kgf} / \mathrm{mm}^{2}$, exercida pela prensa do equipamento por um tempo de aproximadamente 10 minutos.

A etapa de lixamento foi realizada até o grau de acabamento requerido para cada situação. A técnica consistiu em se lixar as amostras sucessivamente com lixas de granulometria cada vez menores, mudando-se a direção de lixamento em $90^{\circ} \mathrm{em}$ cada lixa subsequente até que superfície fica sem risco aparentes. As granulometrias das lixas empregadas foram de 100, 220, 320, 400, 600, 800 e 1.200. Após esta etapa, o polimento foi realizado com pasta diamantada a fim de proporcionar um bom acabamento a superfície, em seguida foi realizada a limpeza com água e álcool etílico. O ataque químico foi realizado com nital a 3\%.

A analise química foi realizada em um espectrômetro de emissão ótica, utilizando tecnologia de detectores CCD, com sistema ótico de faixa espectral de $175 \mathrm{~nm}$ a $590 \mathrm{~nm}$ e câmera de excitação purgada com argônio para analise química de metais em amostras sólidas.

\section{RESULTADOS}

A analise química dos fixadores é mostrada na Tabela 1 e na Figura 2 pode-se visualizar uma comparação entre as amostras. Na Tabela 2 são indicados as médias das durezas medidas nas amostras.

Tabela 1. Composição química dos fixadores analisados

\begin{tabular}{|l|c|c|c|c|c|c|c|c|c|c|c|}
\hline & $\mathrm{C}(\%)$ & $\mathrm{Si}(\%)$ & $\mathrm{Mn}(\%)$ & $\mathrm{P}(\%)$ & $\mathrm{S}(\%)$ & $\mathrm{Cr}(\%)$ & $\mathrm{Mo}(\%)$ & $\mathrm{Ni}(\%)$ & $\mathrm{Al}(\%)$ & $\mathrm{Co}(\%)$ & $\mathrm{Cu}(\%)$ \\
\hline Amostra 1 & 0,46 & 0,213 & 0,68 & 0,026 & 0,019 & 0,057 & 0,002 & 0,023 & 0,021 & 0,014 & 0,052 \\
\hline Amostra 2 & 0,23 & 0,22 & 0,81 & 0,012 & 0,008 & 0,022 & 0,002 & 0,002 & 0,018 & 0,007 & 0,027 \\
\hline Amostra 3 & 0,291 & 1,43 & 1,6 & 0,019 & 0,016 & 0,025 & 0,002 & 0,002 & 0,041 & 0,004 & 0,022 \\
\hline Amostra 4 & 0,234 & 0,197 & 1,47 & 0,015 & 0,006 & 0,023 & 0,002 & 0,004 & 0,039 & 0,005 & 0,014 \\
\hline Amostra 5 & 0,429 & 0,214 & 0,6 & 0,014 & 0,01 & 0,87 & 0,006 & 0,045 & 0,014 & 0,011 & 0,095 \\
\hline
\end{tabular}




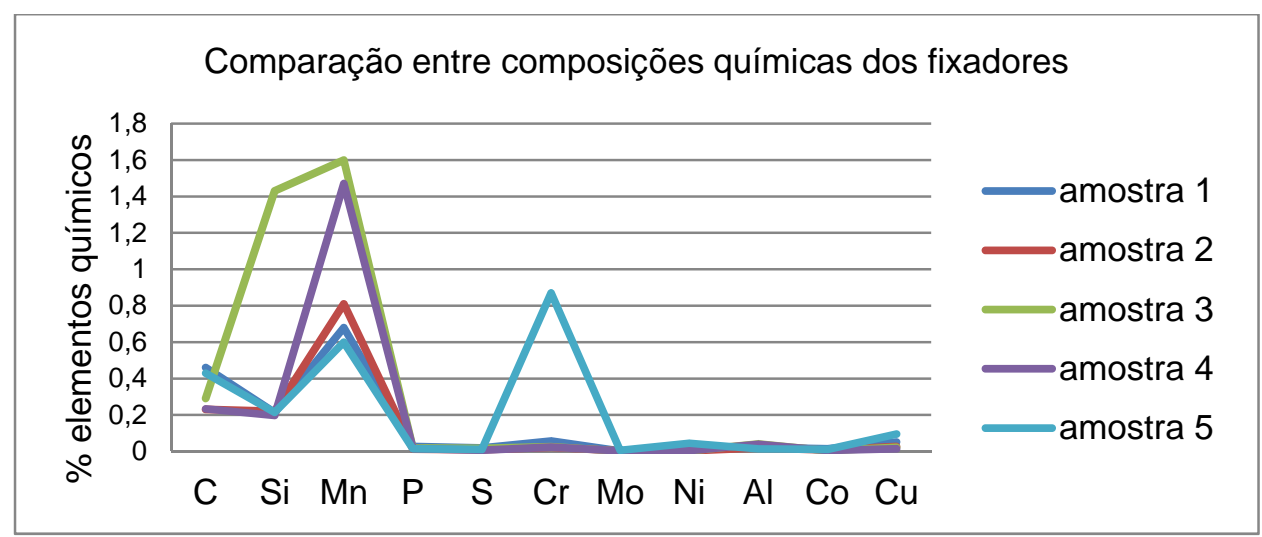

Figura 2. Resultado da analise química das amostras.

Tabela 2. Média das durezas das amostras

\begin{tabular}{|l|l|}
\hline Amostra 1 & $20 \mathrm{HRC}$ \\
\hline Amostra 2 & $26 \mathrm{HRC}$ \\
\hline Amostra 3 & $93 \mathrm{HRB}$ \\
\hline Amostra 4 & $88 \mathrm{HRB}$ \\
\hline Amostra 5 & $18 \mathrm{HRC}$ \\
\hline
\end{tabular}

A micrografia das estruturas das amostras foi gerada por meio de cortes no sentido longitudinal dos fixadores (Figura 3).

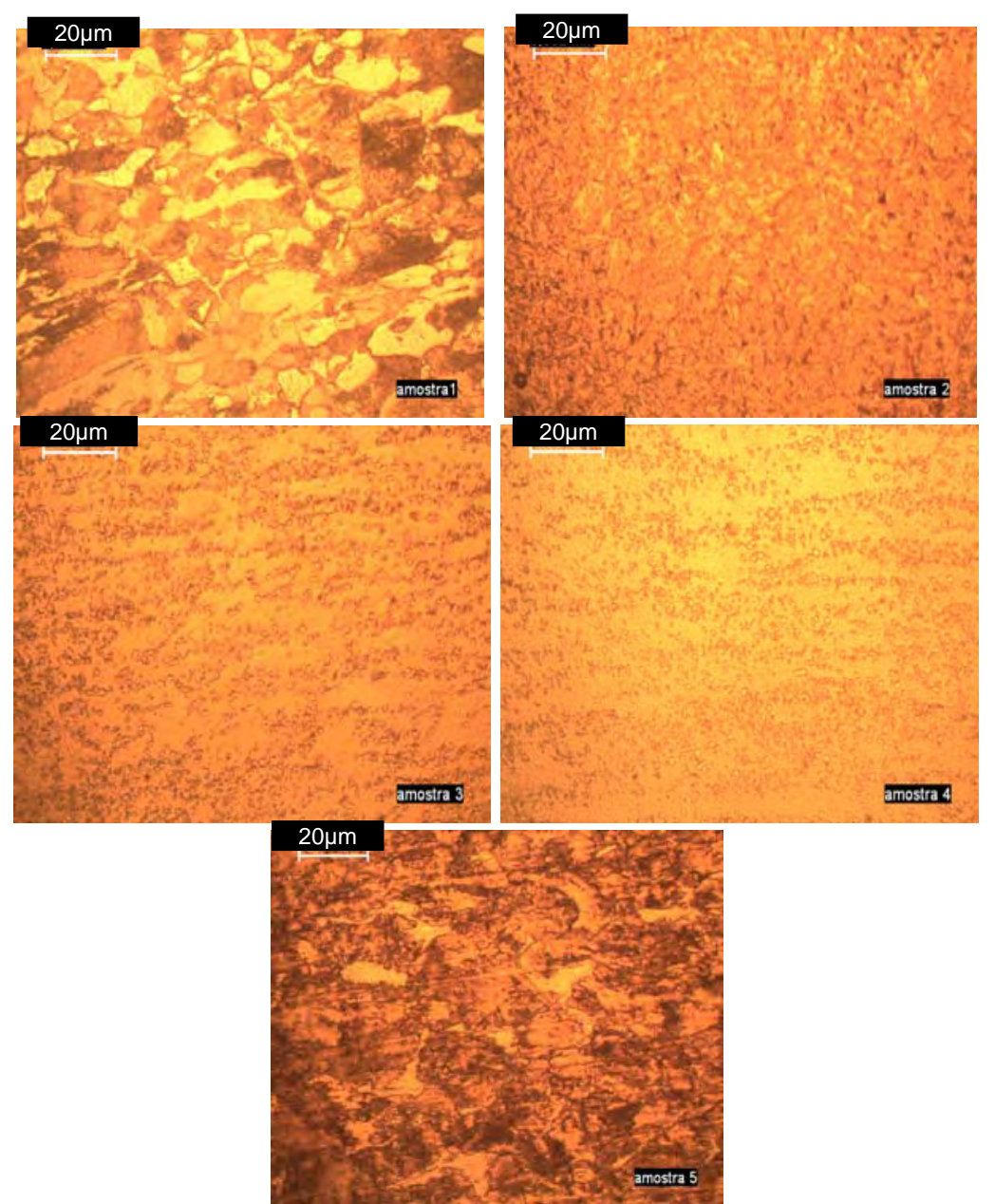

Figura 3. Imagens micrográficas das estruturas dos fixadores. 


\section{DISCUSSÕES}

$\mathrm{Na}$ analise química nota-se que as amostras 1 e 5 apresentam teores mais elevados de carbono, em consequência verifica-se valores de durezas elevadas para estas amostras, quando comparadas com as amostras 3 e 4 . Na amostra 3 visualiza-se uma porcentagem cerca de seis vezes mais do que a médias das demais amostras. Segundo Souza: ${ }^{(8)}$ "o silício nestas proporções associado a teores não elevados de manganês, fósforo e enxofre podem aumentar a dureza e a resistência mecânica, em contra partida a tenacidade diminui".

Além da amostra 3 a amostra 4 apresenta um valor diferenciado de manganês. Souza ${ }^{(8)}$ descreve: "proporcionará melhores propriedades ao impacto", também interessantes nestes elementos que estão sujeitos a estas solicitações.

$\mathrm{Na}$ amostra 5, nota-se um porcentagem muito mais elevada de cromo, comparada com as demais amostras. Neste caso uma explicação possível seja a camada de proteção aplicada na superfície deste fixador.

A micrografia das amostras indicam três diferentes formações. Nas amostras 1 e 5 visualizam-se estruturas formadas por ferrita e pelita. Na amostra 2 tem-se uma estrutura martensítica e nas amostras 3 e 4 as estruturas que formam este material são glóbulos de cementita numa matriz de ferrita, De acordo com Copaert ${ }^{(9)}$ e Padilha e Ambrozio:(10) "típica de coalescimento ou esferoidização".

Os valores das médias das durezas das amostras acompanham as características das microestruturas formadora destes elementos.

\section{CONCLUSÕES}

Neste trabalho teve-se a oportunidade de se verificar a composição química dos fixadores empregados em automóveis provenientes da China, nas amostras observam-se variações entre as montadoras e também entre modelos de uma mesma montadora.

A verificação das durezas dos materiais indicam correlações diretas com as estruturas que formam estes materiais.

As micrografias correspondentes às amostras mostraram três tipos diferentes de estruturas e novamente até mesmo entre os modelos de uma mesma montadora.

Não foram detectadas marcas ou indícios evidentes de desgaste prematuro nas amostras analisadas.

\section{Agradecimentos}

Faculdade de Tecnologia de Sorocaba "José Crespo Gonzales"; Centro Paula Souza; Indústria Mecânica Braspar Ltda.; e CK Ltda.

\section{REFERÊNCIAS}

1 ANFAVEA. Anuário. 2011.

2 SENHA PARA O FUTURO. Anuário Anfavea. 2011.

3 MIRAGAYA, F. Número ainda é tímido, mas carros chineses chegam cada vez mais ao Brasil. Disponível em: http://carros.uol.com.br/ultnot/2010/04/01/numero-ainda-e-timidomas-carros-chineses-chegam-cada-vez-mais-ao-brasil.jhtm. Acesso em: 28 de Nov. de 2011. 
4 CHINESES CRESCERAM 608\% NO BRASIL EM 2010. Disponível em: http://www.oscarroschineses.com.br/chineses-cresceram-608-no-brasil-em-2010/. Acesso em: 28 de Nov. de 2011.

5 PÓLO JUNIOR, A. Os Chineses vêm aí. Disponível em: http://quatrorodas.abril.com.br/reportagens/conteudo_141519.shtml. Acesso em 18 de maio de 2011.

6 ROHDE, R. A. Metalografia preparação de amostras: Uma abordagem prática. versão 3.0. LEMM Laboratório de Ensaios Mecânicos e Materiais, Outubro de 2010.

7 SAMUELS, L. E. Metallographic polishing by mechanical methods. Melbourne \& London Sir Isaac Pitman \& Sons Ltd. Austrália. 1971.

8 SOUZA, S. A. de. Composição química dos aços. São Paulo: Edgard Blucher, 1989.

9 COLPAERT, H. Metalografia dos produtos siderúrgicos comuns. 4. ed. São Paulo: Edgard Blücher, 2008.

10 PADILHA, Â. F.; AMBROZIO, F. F. Técnicas de análise microestrutural. São Paulo: Hemus, 2004. 